\title{
Inhibition of Constitutive Nitric Oxide Synthase (NOS) by Nitric Oxide Generated by Inducible NOS after Lipopolysaccharide Administration Provokes Renal Dysfunction in Rats
}

Doron Schwartz, Margarida Mendonca, Idit Schwartz, Yiyang Xia, Joseph Satriano, Curtis B. Wilson, and Roland C. Blantz ${ }^{*}$

*Division of Nephrology \& Hypertension, University of California, San Diego, San Diego, California 92110; and ${ }^{\ddagger}$ Department of Immunology, The Scripps Research Institute, La Jolla, California 92037

\begin{abstract}
Excess NO generation plays a major role in the hypotension and systemic vasodilatation characteristic of sepsis. Yet the kidney response to sepsis is characterized by vasoconstriction resulting in renal dysfunction. We have examined the roles of inducible nitric oxide synthase (iNOS) and endothelial NOS (eNOS) on the renal effects of lipopolysaccharide administration by comparing the effects of specific iNOS inhibition, L-N ${ }_{6}$-(1-iminoethyl)lysine (L-NIL), and 2,4-diamino6-hydroxy-pyrimidine vs. nonspecific NOS inhibitors (nitroL-arginine-methylester). cGMP responses to carbamylcholine (CCh) (stimulated, basal) and sodium nitroprusside in isolated glomeruli were used as indices of eNOS and guanylate cyclase (GC) activity, respectively. LPS significantly decreased blood pressure and GFR $(112 \pm 4$ vs. $83 \pm 4 \mathrm{mmHg}$; $2.66 \pm 0.29$ vs. $0.96 \pm 0.22 \mathrm{ml} / \mathrm{min}, P<0.05)$ and inhibited the cGMP response to $\mathrm{CCh}$. GC activity was reciprocally increased. L-NIL and 2,4-diamino-6-hydroxy-pyrimidine administration prevented the decrease in GFR $(2.71 \pm 0.28$ and $3.16 \pm 0.18 \mathrm{ml} / \mathrm{min}$, respectively), restored the normal response to $\mathrm{CCh}$, and $\mathrm{GC}$ activity was normalized. In vitro application of L-NIL also restored CCh responses in LPS glomeruli. Neuronal NOS inhibitors verified that $\mathrm{CCh}$ responses reflected eNOS activity. L-NAME, a nonspecific inhibitor, worsened GFR $(0.41 \pm 0.15 \mathrm{ml} / \mathrm{min})$, a reduction that was functional and not related to glomerular thrombosis, and eliminated the $\mathrm{CCh}$ response. No differences were observed in eNOS mRNA expression among the experimental groups. Selective iNOS inhibition prevents reductions in GFR, whereas nonselective inhibition of NOS further decreases GFR. These findings suggest that the decrease in GFR after LPS is due to local inhibition of eNOS by iNOS, possibly via NO autoinhibition. (J. Clin. Invest. 1997. 100:439-448.) Key words: glomerular filtration rate $\bullet$ sepsis $\bullet$ nitric oxide $•$ cGMP
\end{abstract}

\section{Introduction}

Administration of bacterial lipopolysaccharide produces the clinical syndrome of septic shock by initiating a variety of processes including activation of cytokines (1). Pathophysiologic

Address correspondence to Roland C. Blantz, M.D., Professor and Head, Division of Nephrology \& Hypertension, UCSD \& VA Medical Center, 3350 La Jolla Village Dr., San Diego, CA 92161. Phone: 619-552-7528; FAX: 619-552-7549; E-mail: rblantz@ucsd.edu

Received for publication 2 January 1997 and accepted in revised form 22 April 1997.

The Journal of Clinical Investigation

Volume 100, Number 2, July 1997, 439-448 consequences include cellular injury and major cardiovascular effects including hypotension, reduction in systemic vascular resistance, and compromise of renal function.

Previous studies have suggested that the hypotension characteristic of this syndrome is mediated via nitric oxide generation (2). LPS via cytokines can stimulate production of NO by the activation of the inducible form of nitric oxide synthase (iNOS) $)^{1}$ (3). Kilbourn et al. have observed that NO synthesis inhibition with $N$-methyl-L-arginine prevented the TNF-induced hypotension in dogs (4). It has recently been demonstrated that mice lacking iNOS were protected from the cardiovascular collapse induced by LPS (5).

One could presume that the decrease in GFR after LPS administration is a result of the severe systemic hypotension, but careful examination of experimental data leads to the conclusion that it is the result of increased renal vascular resistance (6). The question arises, why does the kidney respond with vasoconstriction in a setting in which there is overproduction of a vasodilator that is known to effect renal vascular resistance (7)? Our laboratory has previously shown that application of NOS inhibitors to normal rats increases blood pressure as well as renal vascular resistance. While the increase of systemic blood pressure after NOS inhibition was not affected by the coadministration of losartan (angiotensin II AT1-selective receptor antagonist) renal vascular resistance was normalized, suggesting that NO in the kidney, in contrast with its role in systemic circulation, is acting as a chronic antagonist of various vasoconstrictors rather than as a primary vasodilator (8). A variety of vasoconstrictors, such as angiotensin II, endothelin-1, and thromboxane $A_{2}$ have been proposed to produce renal vasoconstriction in sepsis $(9,10)$. Intrarenal infusion of ET-1 antiserum ameliorated the renal hypoperfusion in LPS-treated animals (10). It is conceivable that, in spite of the large amounts of NO generated by iNOS, the NO system is unable to counteract the renal vasoconstrictor influences in sepsis. Indeed, renal vasoconstriction after Escherichia coli treatment has been shown to be aggravated by the application of NOS inhibitors (11). Moreover, when nitro-L-arginine-methylester (L-NAME) was administered systemically to LPS-treated rats, extensive glomerular thrombosis has been observed (12).

This study was designed to examine this conundrum, "Why does GFR decrease in a setting in which systemic vascular resistance falls in response to NO overproduction?", by viewing separately the effects of different NOS isoforms. NO has been

\footnotetext{
1. Abbreviations used in this paper: 7NI, 7-nitroindazole; BW, body weight; CCh, carbamylcholine; DAHP, 2,4-diamino-6-hydroxy-pyrimidine; FW, Frömter-Wistar; HYD, hydralazine; L-NAME, nitroL-arginine-methylester; L-NIL, L-N ${ }^{6}$-(1-iminoethyl)lysine (dihydrochloride); NOS, nitric oxide synthase; b-, c-, e-, or iNOS, neuronal, constitutive, endothelial, or inducible NOS; PAS, periodic acid Schiff; SNP, sodium nitroprusside.
} 
demonstrated to exert the capacity to autoinhibit NOS via specific binding sites on the enzyme. Rengasamy and Johns (13) have shown that various NO donors, as well as NO, exhibit the capacity to inhibit all NOS isoform activities in vitro. A significantly lower concentration of $\mathrm{NO}(\sim 10 \mu \mathrm{M})$ was required for inhibition of constitutive NOS than for the inducible isoform $(50-100 \mu \mathrm{M})(14)$. One could anticipate that the substantial concentrations of NO produced by iNOS could autoinhibit the constitutive form of NOS (cNOS) in vivo resulting in a condition in which iNOS is over expressed while cNOS is concurrently inhibited.

A direct effect of LPS on endothelial NOS (eNOS) has also been suggested. However, the exact mechanisms are unclear. Salvemini et al. (15) have shown that LPS activates eNOS, while transcription of eNOS mRNA is decreased in endothelial cells exposed to LPS, as shown by MacNaul and Hutchinson (16).

The current studies were designed to clarify the role of NO, and specifically iNOS and eNOS, on the renal effects of LPS administration. We have examined the systemic and renal effects of the specific vs. nonspecific inhibition of NOS in LPStreated rats. We also examined the activity of glomerular eNOS in vitro by measuring the basal- and agonist-stimulated cGMP levels in isolated glomeruli from animals treated with LPS and specific and nonspecific NOS inhibitors. In addition, we have examined the histological changes within kidneys after exposure to these substances and the effect of LPS and iNOS on the expression of eNOS mRNA in glomeruli.

\section{Methods}

Animal experiments were performed using male Frömter-Wistar (FW) rats weighing $210 \pm 30 \mathrm{~g}$. However, since the FW strain has been reported to have relatively fewer nephrons and develop hypertension, proteinuria, and glomerulosclerosis later in life $(17,18)$, we have duplicated the critical experiments using Wistar rats, as well as confirmed that the FW rats used in these studies did not have proteinuria.

The animals (FW and Wistar rats) were allowed free access to a regular rat pellet diet and tap water. Eight different groups of animals were studied:

Group 1. Untreated controls.

Group 2. LPS. Rats in this group received a single intraperitoneal injection of LPS (serotype 0111:B4; List Biological Labs, Inc., Campbell, CA) at a dose of $0.5 \mathrm{mg} / \mathrm{kg}$ given $8 \mathrm{~h}$ before the initiation of the experimental evaluation.

Group 3. LPS + L-NIL. Rats received LPS at the identical dose as in the previous group, but in addition were given $\mathrm{L}^{-\mathrm{N}^{6}}$-(1-iminoethyl)lysine (dihydrochloride), (L-NIL; Alexis Biochemicals, San Diego, CA) a selective inhibitor of iNOS (19), at a dose of $3 \mathrm{mg} / \mathrm{kg}$ i.p. 36,24 , and $12 \mathrm{~h}$ before LPS, and simultaneously with, and $6 \mathrm{~h}$ after the administration of LPS.

Group 4. LPS + L-NAME. These rats were administered LPS as above and in addition received nitro-L-arginine-methylester* $\mathrm{HCl}$ (Bachem, California, Torrance, CA) $80 \mathrm{mg} /$ liter in the drinking water starting $48 \mathrm{~h}$ before the administration of LPS and $0.5 \mathrm{ml}$ dose i.p. (50 $\mathrm{mg} / \mathrm{kg}$ ) given simultaneously with LPS.

Group 5. LPS + 2,4-diamino-6-hydroxy-pyrimidine. These rats were given LPS as above and in addition received an intraperitoneal injection $(0.5 \mathrm{ml})$ of a different iNOS inhibitor: 2,4-diamino-6-hydroxypyrimidine (DAHP) (Sigma Chemical Co., St. Louis), $15 \mathrm{mg} / \mathrm{kg}$ simultaneously with the LPS. DAHP inhibits GTP-cyclohydrolase 1, which is the rate limiting enzyme of the de novo synthesis of tetrahydrobiopterin $\left(\mathrm{BH}_{4}\right)$, a cofactor required for NOS activity. Recently, DAHP has also been shown to suppress iNOS mRNA and protein expression in a $\mathrm{BH}_{4}$-independent manner (20). Although chronic GTP-cyclohydrolase 1 inhibition for 72 hours has been shown to block endothelial NO synthesis (21), short term administration of DAHP is reasonably selective for iNOS inhibition (22).

Group 6. LPS + L-NIL + hydralazine (HYD) were from Sigma Chemical Co. Rats treated as in group 3 also received IV hydralazine $(\sim 3 \mathrm{mg} / \mathrm{kg}$ body weight $(\mathrm{BW}) / \mathrm{h})$ initiated $30 \mathrm{~min}$ before clearance measurements. The dose of hydralazine was titrated to maintain BP at comparable levels with LPS rats (group 2).

Group 7. L-NIL. These rats received L-NIL as in group 2 without LPS.

Group 8. DAHP. Normal rats received DAHP as in group 5.

\section{Measurement of GFR in the anesthetized rats}

Rats were anesthetized with Inactin (100 mg/kg i.p.; Byk-Gulden, Germany). The animals were placed on a servo-controlled heating table to maintain body temperature at $37^{\circ} \mathrm{C}$. A tracheostomy was performed to facilitate free breathing. The right femoral artery was cannulated to obtain blood samples and monitor arterial pressure (P23Db transducer; Statham Instruments, Oxnard, CA). The right jugular vein was cannulated for the infusion of isotonic $\mathrm{NaCl}-$ $\mathrm{NaHCO}_{3}$ containing $20 \mu \mathrm{Ci} / \mathrm{ml}\left[{ }^{3} \mathrm{H}\right]$ inulin as a marker of GFR. Maintenance solutions were administered at a rate of $1.5 \mathrm{ml} / \mathrm{h}$, and normal rat plasma at a rate of $1.5 \% \mathrm{BW} / \mathrm{h}$ during the first hour and $0.15 \%$ $\mathrm{BW} / \mathrm{h}$ for the remainder of the experiment. The bladder was cannulated for urine collection. After completion of the surgical preparation, the animals were allowed to stabilize for $1 \mathrm{~h}$ before the clearance measurements were initiated. Renal clearance experiments were conducted during three 20-min periods. Arterial blood samples $(160 \mu \mathrm{l})$ were withdrawn at the beginning and end of each urine collection period. The concentration of $\left[{ }^{3} \mathrm{H}\right]$ inulin in plasma and urine was measured by liquid scintillation counting. Inulin clearances were calculated by standard equations (23).

\section{Awake animals studies}

Chronically cannulated rats were prepared as previously described (24). In brief, rats received at least $6 \mathrm{~h}$ of training by sitting quietly in a restraining cage at intervals of not more than $3 \mathrm{~h}$. After the training was completed, animals were anesthetized, catheters were placed in the left femoral artery and vein and bladder. Animals were allowed to recover $7 \mathrm{~d}$ before the initial experiments.

After recovery from the cannulation procedure, rats were divided into two groups. The first group received no treatment, while the second group was administered L-NIL ( $3 \mathrm{mg} / \mathrm{kg}$ i.p. every $12 \mathrm{~h}$ ). $2 \mathrm{~h}$ after the third dose of L-NIL, the animals were placed in a restraining cage and three baseline measurements of GFR were performed following the same protocol used in anesthetized animals. After an additional $24 \mathrm{~h}$, a second set of GFR measurements was performed $8 \mathrm{~h}$ after an intraperitoneal injection of LPS. A higher dose of LPS (1 mg/kg BW) was required to produce a reduction in GFR, which was similar to that observed in anesthetized animals.

\section{Isolation and incubation of glomeruli}

Additional rats were used for these studies. Rats were anesthetized with sodium brevital $(65 \mathrm{mg} / \mathrm{kg}$ i.p.) and killed immediately after removing the kidneys. Kidneys were decapsulated, bisected, and the cortex was carefully dissected free. Glomeruli were prepared using a sieving technique. Cortices were minced to a fine paste with a razor blade and gently pressed through a $106 \mu \mathrm{M}$ stainless steel sieve. The resulting material was suspended in Krebs buffer at $4^{\circ} \mathrm{C}$, which was gassed with $95 \% \mathrm{O}_{2} / 5 \% \mathrm{CO}_{2}$ to maintain a $\mathrm{pH}$ of 7.4 . The buffer consisted of (in mM): $125 \mathrm{NaCl}, 5 \mathrm{KCl}, 1 \mathrm{CaCl}_{2}, 0.75 \mathrm{NaH}_{2} \mathrm{PO}_{4}, 0.75$ $\mathrm{Na}_{2} \mathrm{HPO}_{4}, 0.5 \mathrm{MgCl}_{2}, 10$ glucose, $15 \mathrm{NaHCO}_{3}, 0.1 \mathrm{~L}$-arginine. A phosphodiesterase inhibitor (3-isobutyl-1-methyl-xanthine, $1 \mathrm{mM}$; Sigma Chemical Co.) was routinely included to inhibit c-GMP degradation, thus permitting assessment of cGMP synthesis. The suspension was forced through a 20-gauge needle to decapsulate the glomeruli, and then passed through a $75-\mu \mathrm{m}$ sieve. The glomeruli, which were trapped on the sieve, were washed and pelleted by centrifugation at 
1,000 RPM for $1 \mathrm{~min}$. This was repeated three times. This fraction consisted of $>95 \%$ glomeruli, essentially all of which were decapsulated. The suspension was then aliquoted ( $50 \mu \mathrm{l}$ per tube) and incubated and shaken at $37^{\circ} \mathrm{C}$ for $10 \mathrm{~min}$. The various stimulants were added to a total volume of $100 \mu \mathrm{l}$ and incubated for 2 additional min, after which $100 \mu \mathrm{l}$ of $10 \%$ TCA was added to terminate the reaction. The aliquots were centrifuged at 3,000 RPM, $4^{\circ} \mathrm{C}$ for $20 \mathrm{~min}$. The pellet was extracted in $1 \mathrm{~N} \mathrm{NaOH}$ and used for determination of protein content as previously described (25).

For the assessment of the in vitro effect of L-NIL on glomerular cGMP generation in LPS-treated rats, an L-arginine-depleted buffer was used. The aliquots were preincubated for $10 \mathrm{~min}$ with or without L-NIL $(10 \mu \mathrm{M})$, and then centrifuged. The supernatant was then discarded and the pellet was resuspended with fresh buffer for an additional $4 \mathrm{~min}$, and half of the samples were stimulated with $\mathrm{CCh}$; the other samples were used for assessment of basal cGMP.

The supernatant was ether extracted and lyophilized. The remaining pellet was used for assay of cGMP with a radioimmunoassay kit obtained from Dupont-NEN (Boston, MA).

To examine a possible role of neuronal NOS (bNOS) in the glomerular response to $\mathrm{CCh}$, we repeated the above experiments in control and LPS + L-NIL groups following pretreatment with 7-nitroindazole (7NI; Research Biochemicals, Inc., Natick, MA), a selective bNOS inhibitor. 7NI was dissolved in DMSO and peanut oil (25/ $75 \%$ ), and was administered $(25 \mathrm{mg} / \mathrm{kg}$ i.p. BW) $30 \mathrm{~min}$ before the experiments. This dose has been previously shown to exert an antinociceptive activity and affect tubuloglomerular feedback response, both effects related to bNOS activity. Yet it did not affect systemic blood pressure, suggesting selectivity to neuronal $\operatorname{NOS}(26,27)$.

\section{Nitrite assay}

Nitrites were measured by the addition of $50 \mu \mathrm{l}$ of freshly prepared Griess reagent (1\% sulfanilic acid in $5 \% \mathrm{H}_{3} \mathrm{PO}_{4}$ and $0.1 \% N$-(1-naphtyl ethylene diamine dihydrochloride) in double distilled $\mathrm{H}_{2} \mathrm{O}$, to $50 \mu \mathrm{l}$ of diluted urine sample from the experimental groups (28). Incubation at room temperature for $20 \mathrm{~min}$ followed by spectrophotometric reading at $546 \mathrm{~nm}$. The nitrite concentration was determined from a linear standard curve between 1 and $150 \mu \mathrm{m}$ sodium nitrite. Assays were done in triplicate.

\section{Nitrate assay}

Nitrate in the medium was measured by bioassay using a modification of the method published by Bartholomew (29). Nitrate reductase from $E$. coli was used to reduce nitrate to nitrite. The bacteria was grown for $18 \mathrm{~h}$ under anaerobic conditions after it was washed, resuspended in PBS, and stored in $-70^{\circ} \mathrm{C}$ until use. Nitrates were measured using the Griess reagent as described in Nitrite assay.

\section{Morphologic study}

After termination, renal tissue samples were fixed in 10\% formalin for light microscopy or were snap frozen in liquid nitrogen for immunofluorescence microscopy. The formalin-fixed tissue was embedded in paraffin and sections were stained with periodic acid Schiff (PAS). Cryostat sections of the frozen tissue were stained with FITC-labeled anti-rat fibrinogen antibodies. Histologic studies were done by evaluating 25 glomeruli for neutrophil infiltration, evidence of thrombotic changes, as well as any associated tubulointerstitial change.
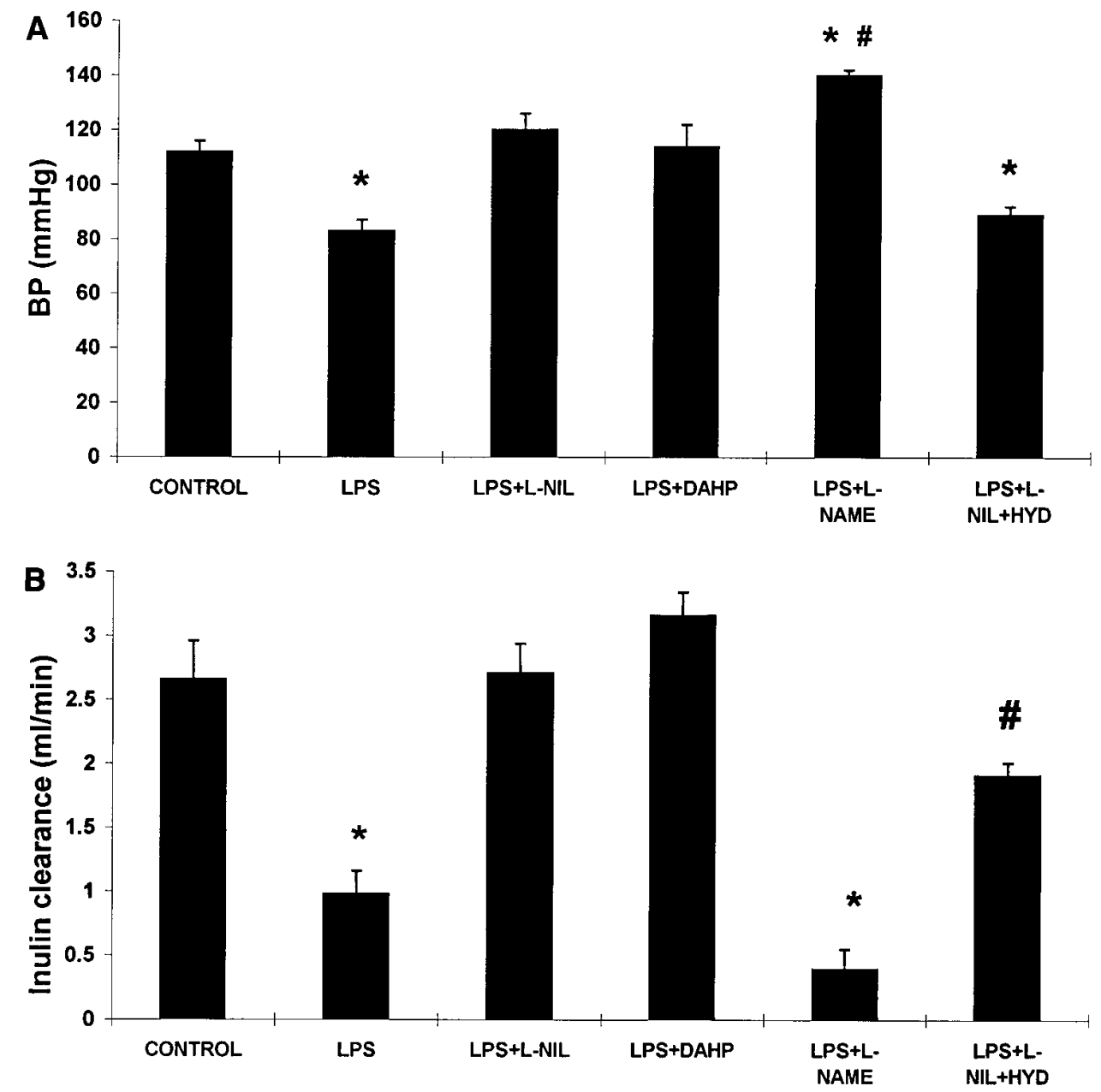

Figure 1. Arterial pressure $(A)$ and GFR $(B)$ of the various experimental groups obtained in anesthetized animals $(n=6)$. See text for definition of groups. GFR is indexed by inulin clearance. Data are presented as the means \pm SEM. $* P<$ 0.01 vs. control, ${ }^{\#} P<0.01$ vs. LPS. 


\section{Assessment of eNOS mRNA}

Glomeruli were isolated from FW rats that received the treatments described above. Glomerular RNA was prepared by a single step method (30), quantitated by its absorption at $260 \mathrm{~nm}$, and then was frozen at $-70^{\circ} \mathrm{C}$. eNOS DNA (a gift from Tadashi Yamamoto, Niigata, Japan) was used for transcription of an antisense riboprobe with incorporation of $\left[{ }^{32} \mathrm{P}\right] \mathrm{UTP}$ (31). A 114-bp probe prepared from rat glyceraldehyde-3-phosphate dehydrogenase (GAPDH) cDNA was used as a housekeeping gene. The RNase protection assay was performed as described previously using a radioanalytic imaging system (AMBIS, Inc., San Diego, CA) (32). The results are presented as the ratio of eNOS counts per minute per GAPDH counts per minute.

\section{Statistical analysis}

Data are presented as the means \pm SEM. Data from the various experiments were subjected to ANOVA. Significance of differences between experimental groups was determined by Student's $t$ test with Bonferroni correction. $P<0.01$ was considered statistically significant.

\section{Results}

In vivo assessments. The results of in vivo studies in anaesthetized animals are depicted in Figs. 1, $A$ and $B$. The administration of LPS resulted in a decrease in blood pressure (112 \pm 4 vs. $80 \pm 4 \mathrm{mmHg}, P<0.01)$, and a major reduction in inulin clearance $(2.66 \pm 0.3$ vs. $0.98 \pm 0.18 \mathrm{ml} / \mathrm{min}, P<0.01)$. The coadministration of L-NAME resulted in higher blood pressures when compared with controls $(140 \pm 2 \mathrm{mmHg})$. However, GFR was further quantitatively reduced, although not statistically different, in FW rats, than values in the LPS animals ( $0.41 \pm 0.15$ vs. $0.96 \pm 0.22 \mathrm{ml} / \mathrm{min}$ ). When L-NIL, an iNOS-specific antagonist, was administered to LPS-treated animals, there was complete normalization of both blood pressure and GFR (120 \pm 6 $\mathrm{mmHg} ; 2.71 \pm 0.28 \mathrm{ml} / \mathrm{min})$. Hydralazine was coadministered to LPS + L-NIL rats to decrease BP values to the LPS group range ( $89 \pm 3$ vs. $83 \pm 4$ ), thus allowing separation of blood pressure versus renal vasoconstriction effects. GFR in LPS + L-NIL + HYD rats was not statistically different from controls, yet it was $100 \%$ greater than in the LPS group (1.91 \pm 0.1 vs. $0.96 \pm 0.22, P<0.01)$. 2,4-Diamino-6-hydroxy-pyrimidine was used as a different selective iNOS inhibitor, acting via a different mechanism. DAHP also normalized blood pressure and GFR when compared with controls (3.16 \pm 0.18 vs. $2.66 \pm 0.3 \mathrm{ml} / \mathrm{min})$. The administration of L-NIL or DAHP alone to normal rats had no effect on either blood pressure or GFR $(124 \pm 3$ and $117 \pm 3 \mathrm{mmHg} ; 2.72 \pm 0.32$ and $2.55 \pm 0.14 \mathrm{ml} /$

Table I. Effects of L-NIL and DAHP in Normal Untreated Rats on Blood Pressure, GFR, and Basal and Stimulated (CCh) Glomerular cGMP Generation

\begin{tabular}{lcclc}
\hline & & & \multicolumn{2}{c}{$\begin{array}{c}\text { Glomerular cGMP } \\
(\mathrm{fm} / \mu \mathrm{g} \text { protein })\end{array}$} \\
\cline { 3 - 5 } \multicolumn{1}{c}{ Group } & $\begin{array}{c}\text { Blood } \\
\text { pressure }\end{array}$ & GFR & Basal & CCh \\
\hline & $m m H g$ & $m l / m i n$ & & \\
Controls $(n=6)$ & $112 \pm 4$ & $2.66 \pm 0.29$ & $0.6 \pm 0.1$ & $1.52 \pm 0.12$ \\
L-NIL $(n=4)$ & $124 \pm 3$ & $2.72 \pm 0.32$ & $0.71 \pm 0.07$ & $1.41 \pm 0.12$ \\
DAPH $(n=4)$ & $117 \pm 3$ & $2.55 \pm 0.14$ & $0.70 \pm 0.05$ & $1.73 \pm 0.14$ \\
& & & &
\end{tabular}

Values are mean \pm SEM. See text for definition of groups.
Table II. Effects of LPS and Selective vs. Nonselective Inhibition of NOS on GFR $(\mathrm{ml} / \mathrm{min})$ : A Comparison between Wistar and Frömter-Wistar Rats

\begin{tabular}{llcll}
\hline & Control & LPS & LPS + L-NIL & LPS + L-NAME \\
\hline Frömter-Wistar & $2.66 \pm 0.3$ & $0.98 \pm 0.18^{*}$ & $2.71 \pm 0.28^{\ddagger}$ & $0.41 \pm 0.15$ \\
Wistar & $2.80 \pm 0.14$ & $1.41 \pm 0.18^{*}$ & $2.59 \pm 0.17^{\ddagger}$ & $0.41 \pm 0.1 * \neq$
\end{tabular}

Values are mean \pm SEM. See text for definition of groups. ${ }^{*} P<0.01$ vs. control, ${ }^{\ddagger} P<0.01$ vs. LPS.

min, respectively) (Table I). We have duplicated these experiments with Wistar rats and produced nearly identical results (Table II). LPS induced a significant decrease in GFR, which was abolished by L-NIL and worsened by L-NAME. Interestingly, the GFR after the coadministration of L-NAME was significantly lower when compared with the LPS group ( $1.41 \pm 0.18$ vs. $0.41 \pm 0.1, P<0.01)$. To summarize: LPS decreased BP and GFR. While all NOS inhibitors prevented the fall in BP, only selective inhibition of iNOS corrected GFR, and nonselective NOS inhibition caused further reductions in GFR.

The effect of L-NIL administration on LPS-treated rats was also studied in awake chronically catheterized rats (Fig. 2, $n=4)$. The administration of LPS resulted in a $50 \%$ decrease in GFR ( $3.02 \pm 0.15$ vs. $1.57 \pm 0.37 \mathrm{ml} / \mathrm{min} P<0.01)$. This decrease was abolished by coadministration of L-NIL (3.20 \pm 0.16 vs. $2.90 \pm 0.19, P=\mathrm{NS})$. Interestingly, in contrast with the anaesthetized studies, LPS did not produce a reduction in blood pressure in awake animals.

LPS significantly increased $\mathrm{NO}_{2} / \mathrm{NO}_{3}$ excretion vs. controls $(0.87 \pm 0.54$ vs. $9.9 \pm 1.9 \mu \mathrm{M} / \mathrm{h}, P<0.001)$ (Fig. 3$)$. Treating the animals with the three different NOS inhibitors, namely L-NIL,

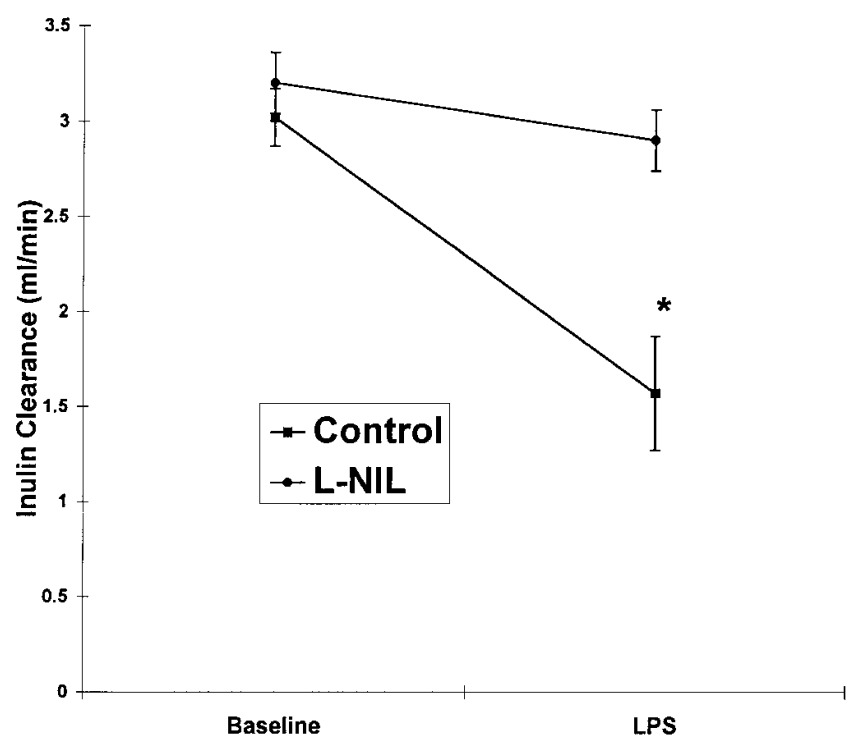

Figure 2. The changes in GFR after the administration of LPS with and without pretreatment with L-NIL in awake, chronically catheterized rats $(n=4)$. See text for definition of groups. GFR is indexed by inulin clearance. Data are presented as the means \pm SEM. $* P<0.01$ vs. baseline. 


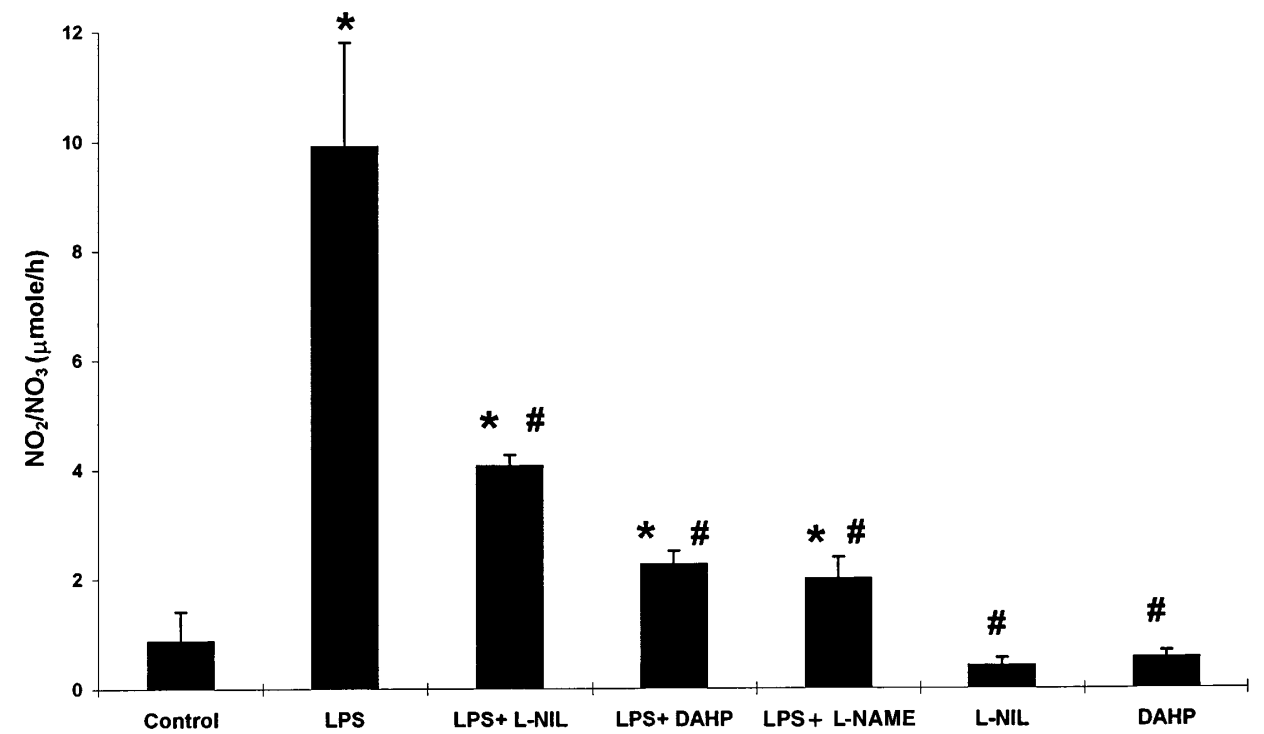

Figure 3. Urinary excretion of $\mathrm{NO}_{2} / \mathrm{NO}_{3}$ during the $8 \mathrm{~h}$ after LPS administration in the various experimental groups. See text for definition of groups. Results shown are mean \pm SEM of triplicate determinations from four different experiments. $* P<0.01$ vs. controls, ${ }^{\#} P<0.01$ vs. LPS.
L-NAME, and DAHP, significantly attenuated the increase in urinary $\mathrm{NO}_{2} / \mathrm{NO}_{3}$ induced by LPS. However, values were still higher than controls. The in vivo administration of either L-NIL or DAHP to normal rats did not affect urinary $\mathrm{NO}_{2} / \mathrm{NO}_{3}$ excretion when compared with controls.

In vitro assessments. To examine the activity of glomerular eNOS, we compared basal cGMP generation and cGMP responses with stimulation by carbamylcholine $(\mathrm{CCh})$, a cNOS agonist, in freshly harvested glomerular suspensions (Fig. 4). Basal cGMP levels in the LPS group were three times higher than controls $(0.6 \pm 0.1$ vs. $1.8 \pm 0.1 \mathrm{fm} \mathrm{cGMP} / \mu \mathrm{g}$, protein, $P<$ 0.01 ), while no significant differences were observed between the LPS + L-NAME, LPS + L-NIL, and controls (0.98 \pm 0.17 , $0.62 \pm 0.08$, and $0.6 \pm 0.1 \mathrm{fm} c G M P / \mu g$ protein, respectively). The absolute increase in cGMP generation compared with cor- responding basal levels after $\mathrm{CCh}$ stimulation (CCh responsiveness) in LPS-treated rats was diminished by $50 \%$ as compared with controls $(0.93 \pm 0.11$ vs. $0.39 \pm 0.08 \mathrm{fm} \mathrm{cGMP} / \mu \mathrm{g}$ protein, $P<0.01)$. No response to $\mathrm{CCh}$ was observed when L-NAME was administered after LPS $(0.06 \pm 0.03 \mathrm{fm} \mathrm{cGMP} / \mu \mathrm{g}$ protein). The rats that received LPS and L-NIL or LPS and DAHP exhibited the same responses as controls, as evidenced by a normal response to $\mathrm{CCh}(0.94 \pm 0.16$ and $1.19 \pm 0.33 \mathrm{fm}$ $\mathrm{cGMP} / \mu \mathrm{g}$ protein). The in vivo administration of either L-NIL or DAHP to normal rats, both previously shown in vitro to inhibit iNOS, did not affect basal- or CCh-stimulated cGMP generation in glomeruli isolated from these animals, demonstrating that those agents acted as selective inhibitors of iNOS in in vivo experiments as well (Table I).

We also examined the effect of L-NIL administered in vitro

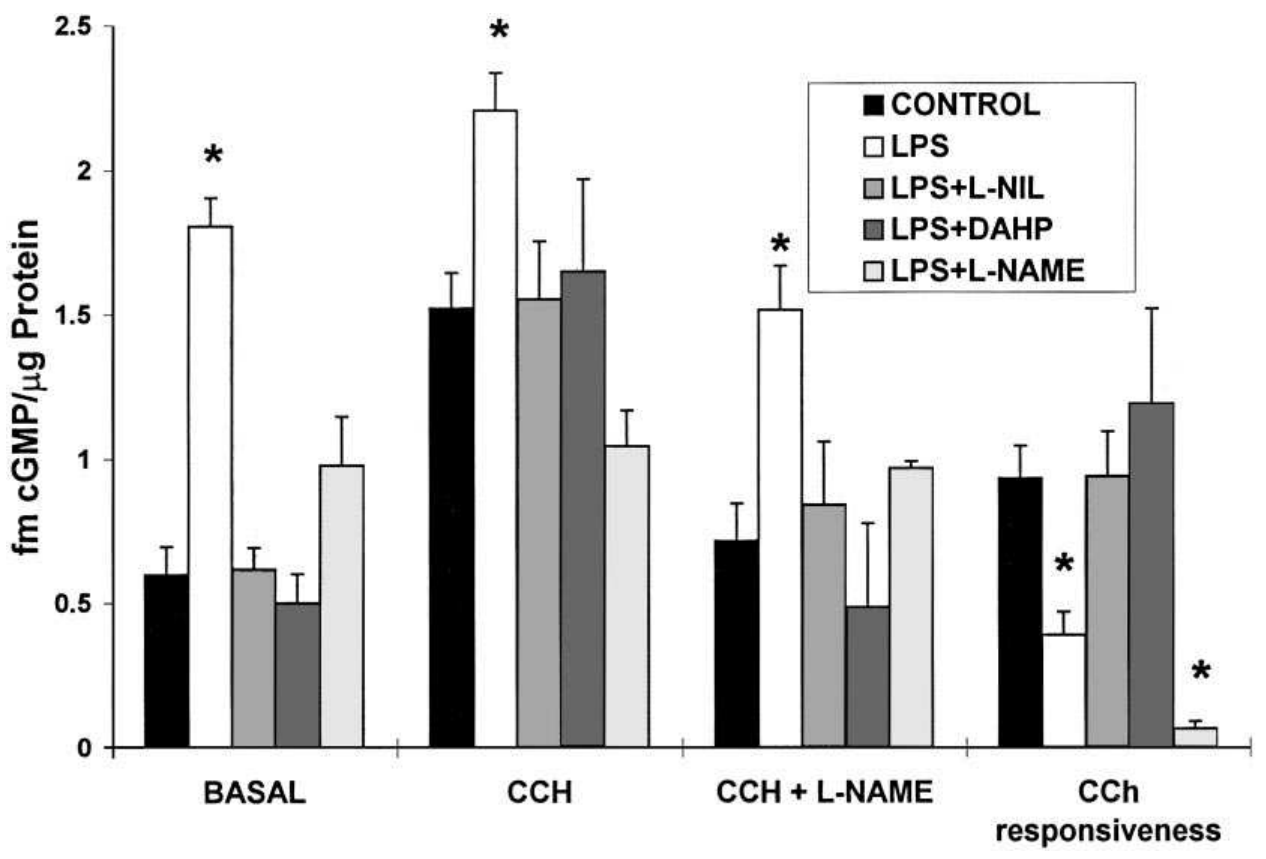

Figure 4. Glomeruli were isolated from the different experimental groups. After 10 min of preincubation in the presence of absence of $0.5 \mathrm{mM}$ L-NAME, CCh (an eNOS agonist) was added for additional $2 \mathrm{~min}$. CCh responsiveness, an index of eNOS activity, represents the incremental cGMP generated after CCh administration (stimulated, basal). Results shown are mean \pm SEM of duplicate determinations from four separate experiments. $* P<0.01$ was considered statistically significant. See text for definition of groups. 


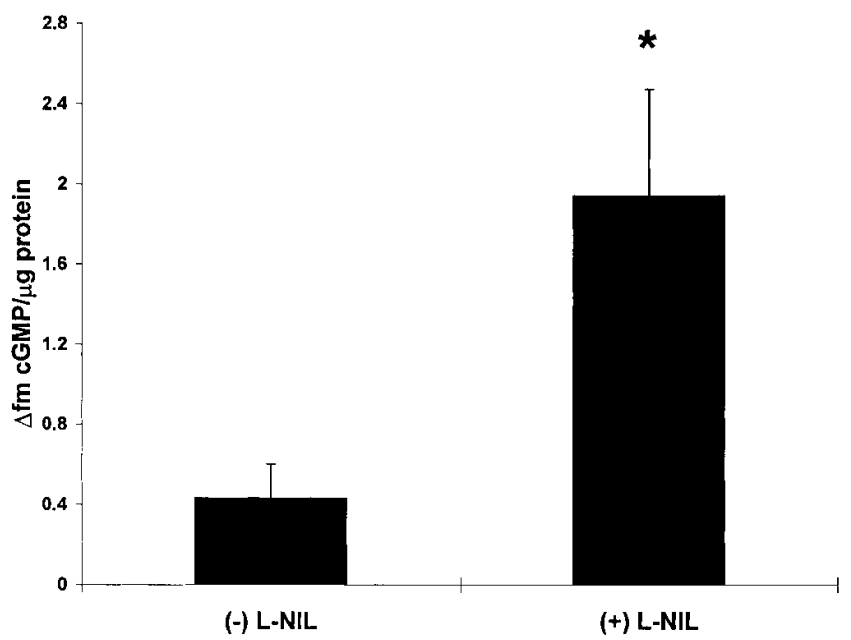

Figure 5. CCh responsiveness in glomeruli isolated from LPS-treated rats with and without ex vivo administration of L-NIL $(n=4)$. Results shown are mean \pm SEM of duplicate determinations from four separate experiments. ${ }^{*} P<0.02$ was considered statistically significant.

to glomeruli harvested from LPS-treated rats on the response to CCh $(n=4$, Fig. 5). The administration of L-NIL to glomeruli derived from LPS-treated rats resulted in a significantly higher $\mathrm{CCh}$ responsiveness (stimulated, basal) as compared with nontreated suspensions $(1.94 \pm 0.53$ vs. $0.44 \pm 0.16 \mathrm{fm}$ $\mathrm{cGMP} / \mu \mathrm{g}$ protein, $P<0.02$ ), suggesting that this effect was reversible in vitro by reducing iNOS-induced NO generation.

Since CCh stimulates both eNOS and bNOS, we evaluated the glomerular response to $\mathrm{CCh}$ in the two experimental groups that exhibited a normal response to $\mathrm{CCh}$ (controls and LPS + L-NIL) after pretreatment with 7NI, a selective bNOS inhibitor $(n=4)$. CCh induced a $4.4 \pm 0.43$-fold increase in cGMP generation in $7 \mathrm{NI}$-treated rats vs. $4.75 \pm 0.57$ in vehicletreated animals $(P=\mathrm{NS})$. The application of 7NI to LPS +
L-NIL-treated rats resulted in a CCh response that was equal to or higher than in LPS + L-NIL rats. These data suggest that glomerular cGMP generation after $\mathrm{CCh}$ stimulation in these studies is predominantly derived from endothelial NOS.

We evaluated the activity of guanylate cyclase by examining the effect of SNP on cGMP production by glomerular incubates in the respective experimental groups (Fig. 6). The cGMP responses to sodium nitroprusside (SNP) in the groups that exhibited a decreased response to $\mathrm{CCH}$, namely LPS and LPS + L-NAME, were significantly higher than controls ( $7.03 \pm 1$ and $9.45 \pm 1.95$ vs. $3.57 \pm 0.49 \mathrm{fm} \mathrm{cGMP} / \mu \mathrm{g}$ protein, respectively, $P<0.01)$.

The coadministration of L-NIL to LPS-treated animals resulted in a smaller but not significant increase in cGMP production after SNP compared with controls.

Histologic assessment (Fig. 7). Studies using LPS + L-NAME, LPS + L-NIL, LPS alone, and untreated controls were performed in FW rats ( $n=3$ /group) and Wistar rats $(n=$ 5/group). A small increase in neutrophils was found in all rats receiving LPS (0.72-1.56 neutrophils/glomerulus), compared with controls (0.25-0.44 neutrophils/glomerulus). Accumulations of intraluminal PAS-positive material characteristic of fibrin in glomerular capillaries were observed inconsistently in the LPS-treated rats. In the three FW rats given LPS + L-NAME, PAS positive intraluminal material was found in 22/ $2510 / 25$, and $1 / 25$ glomeruli. In the other FW groups, one rat in the LPS + L-NIL and one in the LPS alone had 1/25 glomeruli with intraluminal material. In the Wistar rats, intraluminal material characteristic of fibrin was not found in more than $1-2 / 25$ glomeruli in an occasional rat given LPS with or without additional agent by either PAS staining or immunofluorescence. The finding was present in one rat given LPS, one given LPS + L-NAME, and one rat given LPS + L-NIL. The minimal amounts of intraluminal material observed could not explain the glomerular functional changes. Occasional areas of protein reabsorption droplets, intraluminal casts, and slight vacuolation of tubular epithelial cells were noted in the rats in both groups that received LPS with or without other treatments.

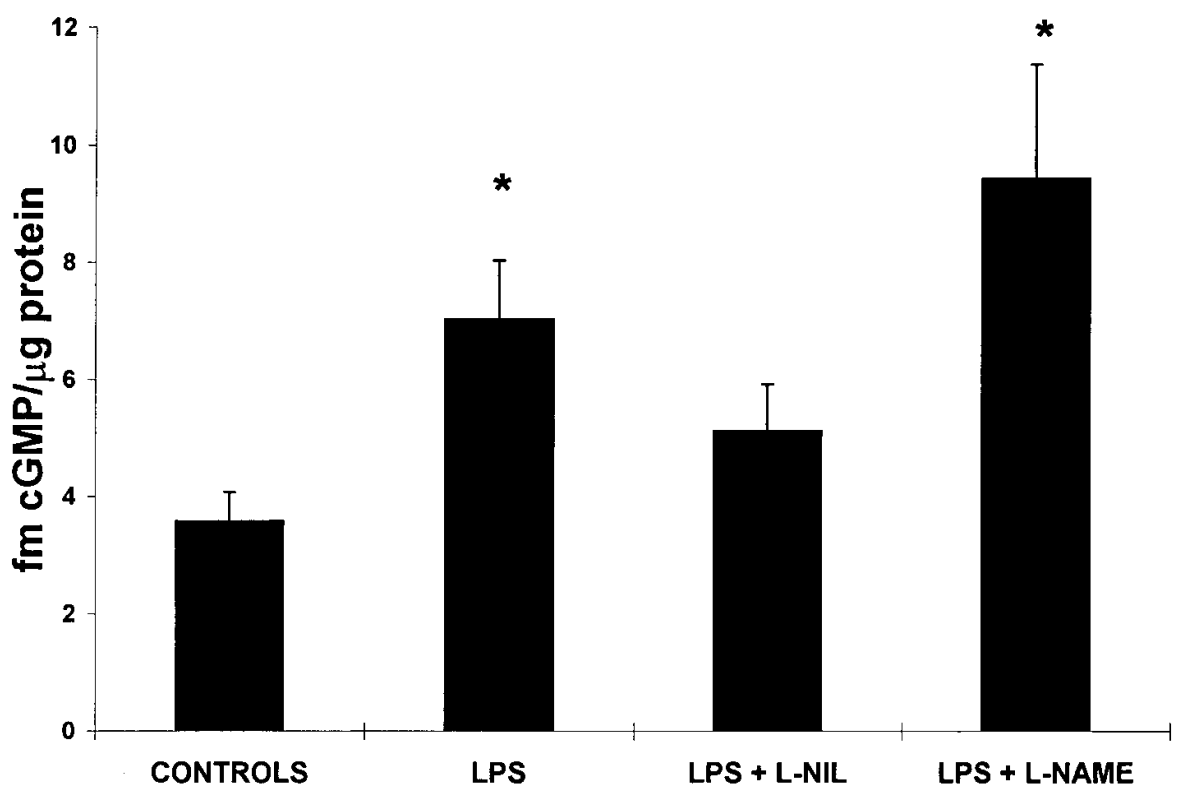

Figure 6. Glomeruli were incubated as described in Fig. 3, and then exposed to $10 \mathrm{mM}$ SNP for 2 min to study the state of activation of guanylate cyclase. Results are mean \pm SEM of duplicate determinations from four separate experiments. $* P<0.01$ was considered to be statistically significant. 

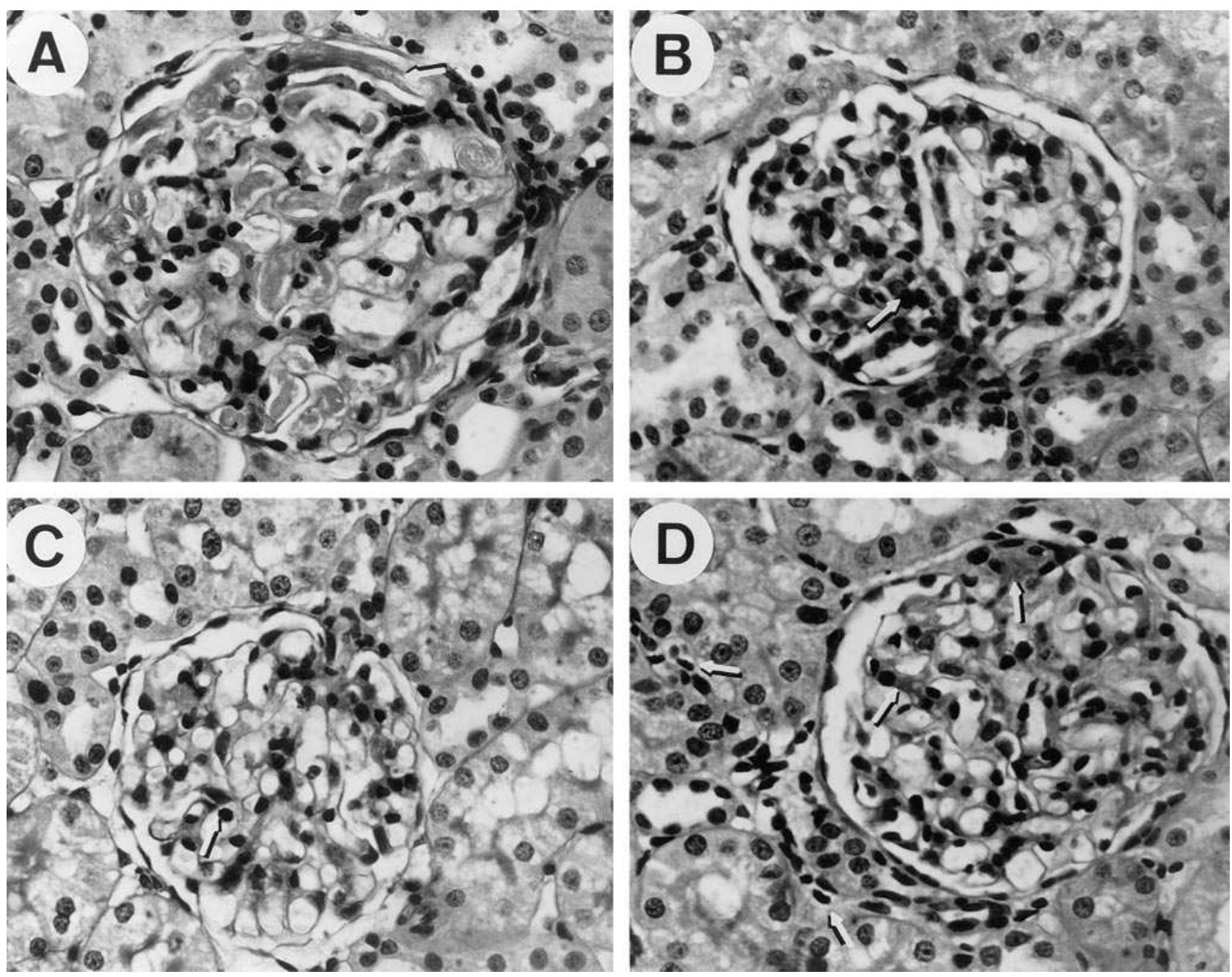

Figure 7. This figure illustrates some of the histologic findings outlined in Results. (A) Some glomeruli had evidence of fibrin plugs (arrow) in glomerular capillaries as in this FW rat given LPS + L-NAME. (B) The more typical lesion in rats given LPS + L-NAME was an increase in neutrophils (arrow) in the glomerulus as in this Wistar rat. (C) A small increase in neutrophils (arrow) was also found after LPS + L-NIL as in this Wistar rat. $(D)$ The young FW control rats had a mild background renal lesion with focal increases in glomerular cells, areas of increased mesangial matrix (arrow), and tubular changes including interstitial infiltrates (arrow). (The lesion increases in extent and severity as the FW rats age, see text.) Original magnification $520 \times$, periodic Schiff stain.

Of interest, the FW rats were found to have glomerular and tubular abnormalities characterized by focal increases in glomerular cells, increased mesangial matrix, focal thickening of tubular basement membranes, and adjacent connective tissue with focal chronic inflammatory infiltrates. Proteinuria, hypertension, and glomerulosclerosis have been reported in this strain with the suggestion that the rats have fewer than normal glomeruli, which predispose them to these changes $(17,18)$. In ongoing studies in our laboratories, the lesion starts early in life, involves both sexes, and becomes progressively worse with age. For these reasons, studies were performed in younger FW rats.

RNase protection assay. The results of the RNase protection assay, expressed as eNOS vs. GAPDH ratio, revealed no significant difference in the expression of mRNA for eNOS in glomeruli from the respective experimental groups, which was

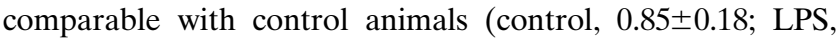

$0.85 \pm 0.24 ;$ LPS + L-NIL, $0.75 \pm 0.05 ;$ LPS + L-NAME, $0.9 \pm$ $0.09 ; n=3$; Fig. 8).

\section{Discussion}

Induction of nitric oxide synthase is critical to the syndrome recognized as sepsis after the administration of bacterial lipopolysaccharide (1-4). In the current experiments, administration of LPS produced major increases in urinary $\mathrm{NO}_{2} / \mathrm{NO}_{3}$ excretion. NOS inhibitors decreased $\mathrm{NO}_{2} / \mathrm{NO}_{3}$ excretion, confirming that the increased nitrite excretion derived from NOS activation. The sepsis syndrome that followed LPS administration resulted in significant reductions in blood pressure and GFR, but created no major histological changes, suggesting that the GFR reduction was a functional event resulting partially from hypotension but primarily from renal vasoconstriction. Earlier studies have demonstrated that application of an 


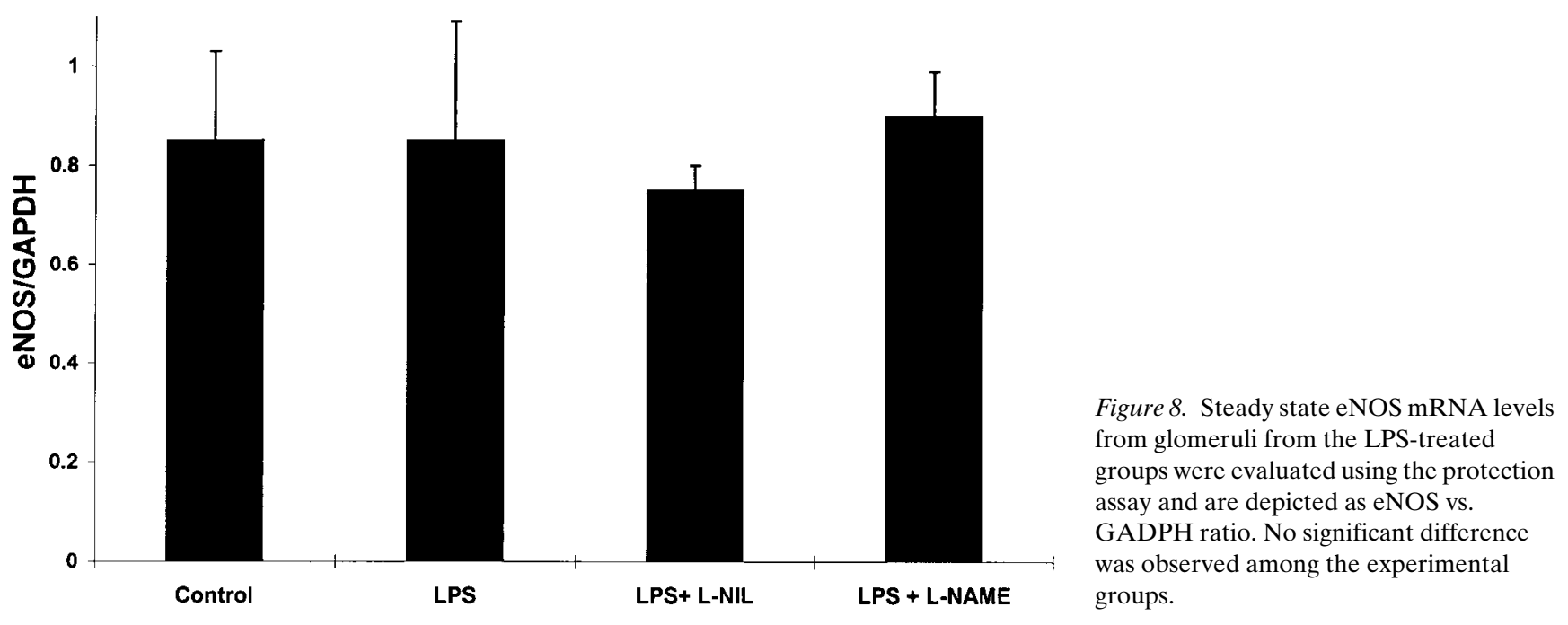

NOS inhibitor to animal models of sepsis restores normal blood pressure but leads to more severe reductions in GFR, importantly related to significant glomerular thrombosis as well as renal vasoconstriction $(11,12)$. We have verified these observations in the current studies. However, because the NOS inhibitors were nonselective, we chose to administer additional agents that selectively inhibit iNOS, namely L-NIL or DAHP, to LPS-treated rats. L-NIL decreased urinary $\mathrm{NO}_{2} /$ $\mathrm{NO}_{3}$ excretion after LPS administration yet did not alter the normal glomerular response to an eNOS agonist, confirming that this agent acted in our experiments as a selective iNOS inhibitor. This treatment resulted in prevention of both the reduction in arterial pressure and GFR without significant evidence of glomerular thrombosis. We also found that using an alternate mechanism of inhibiting iNOS activity, the administration of DAHP, a GTP cyclohydrolase inhibitor, also prevented the reduction of GFR. DAHP markedly reduces intracellular tetrahydrobiopterin $\left(\mathrm{BH}_{4}\right)$ levels, and has been reported to prevent the transcription of iNOS mRNA after LPS (20). This substance alone also did not affect glomerular eNOS activity.

Since L-NIL administration prevented hypotension, we chose to examine the effect of coadministration of hydralazine in order to decrease blood pressure to levels comparable with that following administration of LPS alone. The coadministration of hydralazine to LPS + L-NIL rats reduced blood pressure to values achieved in LPS rats, yet this degree of hypotension did not significantly affect GFR, which remained in the normal range. These data collectively suggest that selective inhibition of iNOS by L-NIL or DAHP preserved renal function in this model by a local renal effect rather than by normalizing blood pressure. These results stand in contrast to the findings after nonselective inhibition of NOS, which resulted in a significant decrease in renal function. In spite of the absence of glomerular thrombotic events, the decrease in GFR in the Wistar LPS + L-NAME group was of significantly greater magnitude than the LPS group, implying that glomerular thrombosis did not play a critical role in the decrease in GFR in our model and supporting a hemodynamic or functional mechanism. These results do not contradict the observations of Shultz and Raij (12), since the doses of L-NAME used in the current study were a magnitude lower than they had used.

Some controversy exists in the literature regarding the role of NO in renal hemodynamics of anesthetized vs. awake animals. While De Nicola et al. have shown that endogenous angiotensin II mediates some of the glomerular hemodynamic responses to acute systemic NO inhibition in anesthetized rats (8), Baylis et al. have found that, in the conscious rat, renal hemodynamic response to NO blockade was not mediated by endogenous angiotensin II (33). Therefore, we duplicated the critical experiments in awake chronically catheterized rats. Similar to the results in the anesthetized rats, L-NIL abolished the reduction in GFR produced by LPS, implying that the renoprotective effect of selective iNOS inhibition is indeed a universal one.

We have evaluated glomerular cGMP production as a marker of NOS activity, both in the basal condition and after agonist stimulation. Carbamylcholine has been shown to increase cGMP generation by stimulation of calcium-dependent NO synthase systems (eNOS and bNOS) (34). Administration of LPS to rats resulted in a threefold increase in basal cGMP generation, probably an underestimate of the increase in vivo since these studies were performed in vitro in freshly harvested glomeruli. However, the response to $\mathrm{CCh}$, which was shown in our experiments to reflect predominantly glomerular eNOS activity, was markedly diminished in those animals receiving LPS alone when compared with controls. However, when L-NIL was administered to LPS-treated rats, both in vivo and in vitro, basal levels of cGMP as well as the response to CCh were completely normalized, suggesting intact and stimulatable eNOS activity. These results imply that selective inhibition of iNOS in rats receiving LPS restores the normal responsivity of glomerular eNOS. One can conclude that the reduction in GFR that occurs after LPS administration is not due to an overall reduction in glomerular $\mathrm{NO}$ generation since basal cGMP levels were significantly higher than the LPS + L-NIL rats. In fact, the reduction in GFR correlates best with the functional inhibition of eNOS activity. Previous studies have shown that $E$. coli endotoxemia diminishes the vasodilator response to acetylcholine in ex vivo perfused aorta, and this ob- 
servation was associated with a decrease in NO generation, supporting the hypothesis that eNOS activity is inhibited in sepsis (35).

Glomeruli were incubated with SNP to assess the activity of guanylate cyclase within cells. Significantly higher cGMP levels were obtained after SNP stimulation in both LPS and LPS + L-NAME rats, the two groups that were characterized by inhibition of eNOS activity. In contrast, cGMP responses to SNP were not different between controls and LPS + L-NIL rats. These observations suggest that the decrease in agoniststimulated cGMP generation observed after LPS and in LPS + L-NAME groups is secondary to inhibition of eNOS and not due to reductions in guanylate cyclase activity. In fact, guanylate cyclase activity was increased after SNP in these groups, possibly as a compensatory response to the decreased activity of eNOS within glomeruli. These results are in agreement with Moncada et al., who demonstrated that inhibition of vascular nitric oxide synthesis produced supersensitivity to nitrovasodilators (36). These results further suggest that the reduction in cGMP generation after CCh in LPS and LPS + L-NAME groups was logically the result of inhibition of eNOS activity rather than the consequence of a toxic effect of LPS on the generalized enzyme activity of these cells.

An alternative mechanism of eNOS inhibition involves effects of LPS and cytokines on eNOS mRNA levels. Transcription of eNOS mRNA was shown to decrease in endothelial cells exposed to LPS (16). Also, TNF $\alpha$ can reduce eNOS mRNA by shortening its half-life from $\sim 48$ to $\sim 3 \mathrm{~h}$ (37). No significant difference was observed in steady state glomerular eNOS mRNA levels among the experimental groups, implying that the apparent reduction in eNOS activity was not related to decreased mRNA expression.

It is clear from the present data that the adverse renal outcomes after LPS correlate best with suppression of constitutive NOS activity rather than with the elevated basal NO generation as indexed by basal glomerular cGMP. The overall findings are best explained as follows: one must consider both autocrine and paracrine effects of NO. The cells that exhibit activation of iNOS after LPS are not necessarily the same cells that serve as the major targets for NO and eNOS activity. It is generally understood that suppression of cNOS activity might lead to renal vasoconstriction (8). In addition, suppression of the autocrine function of cNOS might also alter the behavior of cells such as platelets, smooth muscle cells, and endothelial cells. The high basal NO activity after LPS may be a reflection of overproduction of NO by a selective minority of cells induced to transcribe iNOS. This activation would flood the local environment with elevated levels of NO, which clearly exert the capacity to autoinhibit constitutive eNOS (15) without inhibiting iNOS, since the NO concentrations required to inhibit iNOS are much higher (14). Local overproduction of NO by iNOS may downregulate eNOS by autoinhibition and contribute to vasoconstriction, and even the cell adhesiveness contributing to glomerular thrombosis. That this formulation has credence is supported by the finding that guanylate cyclase activity as indexed by cGMP responses to SNP was upregulated after both L-NAME and LPS administration. Guanylate cyclase normally up- and downregulates in inverse relation to NO levels $(36,38)$. This finding suggests that upregulation of guanylate cyclase is occurring primarily in response to inhibition of eNOS activity rather than in direct response to the total $\mathrm{NO}$ in the environment.
Westberg et al. have shown that the administration of an NO donor to LPS + L-NAME-treated rats prevented glomerular thrombosis (39). When we administered L-NIL to LPStreated rats, only minimal thrombosis was evident. The question arises whether glomerular thrombosis is also a result of eNOS inhibition or is it the decrease in NO that can no longer counteract the renal vasoconstriction and activation of procoagulant factors that accounts for these deleterious events. We did not monitor NO levels at multiple time periods during the $8 \mathrm{~h}$ after exposure to LPS. It is possible that at some period during these $8 \mathrm{~h}$, NO levels in the L-NAME group were significantly lower than in L-NIL-treated and other groups, thereby producing thrombotic events. We have clearly demonstrated that the level of inhibition of iNOS produced by L-NIL did not produce significant glomerular thrombosis and did normalize GFR.

Septic shock is the leading cause of death in intensive care units (40). NOS inhibitors have prevented the hypotension in septic patients and in animal models. However, nonspecific NOS inhibitors have not improved and have even worsened survival. Cobb et al. showed that L-NAME increased systemic vascular resistance, but mortality rates increased in awake canines pretreated with endotoxin (41). Harbrecht et al. found that nonselective inhibition of NO synthesis during endotoxemia promoted intrahepatic thrombosis (42). We propose that selective inhibition of iNOS could represent a substantially superior approach for the treatment of the sepsis syndrome. In contrast with nonselective NOS inhibition, selective iNOS inhibition stabilizes blood pressure, improves renal function, and does not produce thrombosis.

In conclusion, induction of iNOS in LPS-treated animals is associated with hypotension, reduction in GFR, and inhibition of the glomerular endothelial NOS. Selective inhibition of iNOS prevents the fall in blood pressure and the decrease in GFR and restores normal eNOS activity. Nonselective inhibition of NOS further decreases GFR. These studies suggest important and complex interactions between NOS isoforms after LPS that significantly impact upon blood pressure, renal function, and thrombotic events.

\section{Acknowledgments}

These studies were supported by grants from the National Institutes of Health (DK-28602, HL-48018, and DK-20043) and funds provided by the Office of Research and Development, Medical Research Service of the Department of Veterans Affairs. Dr. Schwartz was funded in part by an Institutional Fellowship from the National Kidney Foundation of Southern California.

\section{References}

1. Bone, R.C. 1991. The pathogenesis of sepsis. Ann. Intern. Med. 115:457-469.

2. Thiemermann, C., and J. Vane. 1990. Inhibition of nitric oxide synthesis reduces the hypotension induced by bacterial lipopolysaccharide in the rat in vivo. Eur. J. Pharmacol. 182:591-595.

3. Palmer, R.M.J. 1993. The discovery of nitric oxide in the vessel wall: a unifying concept in the pathogenesis of sepsis. Arch. Surg. 128:396-401.

4. Kilbourn, R.G., S.S. Gross, A. Jubran, J. Adams, O.W. Griffith, R. Levi, and R.F. Lodato. 1990. $N^{\mathrm{G}}$-methyl-L-arginine inhibits tumor necrosis factorinduced hypotension: implications for the involvement of nitric oxide. Proc. Natl. Acad. Sci. USA. 87:3629-3632.

5. MacMicking, J.D., C. Nathan, G. Hom, N. Chartrain, D.S. Fletcher, M. Trumbauer, K. Stevens, Q.W. Xie, K. Sokol, N. Hutchinson, H. Chen, and J.S. Mudgett. 1995. Altered responses to bacterial infection and endotoxic shock in mice lacking inducible nitric oxide synthase. Cell. 81:641-650.

6. Fink, M.P., V. Fiallo, K.L. Stein, and W.M. Gardiner. 1987. Systemic and 
regional hemodynamic changes after intraperitoneal endotoxin in rabbits: development of a new model of the clinical syndrome of hyperdynamic sepsis. Circ. Shock. 22:73-81.

7. Baylis, C., P. Harton, and K. Engles. 1990. Endothelial derived relaxing factor controls renal hemodynamics in the normal rat kidney. J. Am. Soc. Nephrol. 1:875-881.

8. De Nicola, L., R.C. Blantz, and F.B. Gabbai. 1992. Nitric oxide and angiotensin II. Glomerular and tubular interaction in the rat. J. Clin. Invest. 89: 1248-1256.

9. Cumming, A.D., A.A. Driedger, J.W. McDonald, R.M. Lindsay, K. Solez, and A.L. Linton. 1988. Vasoactive hormones in the renal response to systemic sepsis. Am. J. Kid. Dis. 11:23-32.

10. Badr, K.F. 1992. Sepsis-associated renal vasoconstriction: potential targets for future therapy. Am. J. Kidney Dis. 20:207-213.

11. Spain, D.A., M.A. Wilson, I.T.M. Bloom, and R.N. Garrison. 1994. Renal microvascular responses to sepsis are dependent on nitric oxide. J. Surg. Res. 56:524-529.

12. Shultz, P.J., and L. Raij. 1992. Endogenously synthesized nitric oxide prevents endotoxin-induced glomerular thrombosis. J. Clin. Invest. 90:17181725 .

13. Rengasamy, A., and R.A. Johns. 1993. Regulation of nitric oxide synthase by nitric oxide. Mol. Pharmacol. 44:124-128.

14. Griscavage, J.M., N.E. Rogers, M.P. Sherman, and L.J. Ignarro. 1993. Inducible nitric oxide synthase from a rat alveolar macrophage cell line is inhibited by nitric oxide. J. Immunol. 151:6329-6337.

15. Salvemini, D., R. Korbut, E. Anggard, and J. Vane. 1990. Immediate release of a nitric oxide-like factor from bovine aortic endothelial cells by Escherichia coli lipopolysaccharide. Proc. Natl. Acad. Sci. USA. 87:2593-2597.

16. MacNaul, K.L., and N.I. Hutchinson. 1993. Differential expression of iNOS and cNOS mRNA in human vascular smooth muscle cells and endothelial cells under normal and inflammatory conditions. Biochem. Biophys. Res. Commun. 196:1330-1334.

17. Remuzzi, A., S. Puntorieri, M. Alfano, D. Macconi, M. Abbate, T. Bertani, and G. Remuzzi. 1992. Pathophysiologic implications of proteinuria in a rat model of progressive glomerular injury. Lab. Invest. 67:572-579.

18. Remuzzi, A., S. Puntorieri, A. Mazzoleni, and G. Remuzzi. 1988. Sex related differences in glomerular ultrafiltration and proteinura in Munich-Wistar rats. Kidney Int. 34:481-486.

19. Moore, W.M., R.K. Webber, G.M. Jerome, F.S. Tjoeng, T.P. Misko, and M.G. Currie. 1994. L- $N^{6}$-(1-iminoethyl)lysine: a selective inhibitor of inducible nitric oxide synthase. J. Med. Chem. 37:3886-3888.

20. Bogdan, C., E. Werner, S. Stenger, H. Wachter, M. Rollinghoff, and G.W. Felmayer. 1995. 2,4-Diamino-6-hydroxypyrimidine, an inhibitor of tetrahydrobiopterin synthesis, downregulates the expression of iNOS protein and mRNA in primary murine macrophages. FEBS Lett. 363:69-74.

21. Schmidt, K., E.R. Werner, B. Mayer, H. Wachter, and W.R. Kukovetz. 1992. Tetrahydrobiopterin-dependent formation of endothelium-derived relaxing factor (nitric oxide) in aortic endothelial cells. Biochem. J. 281:297-300.

22. Gross, S.S., and R. Levi. 1992. Tetrahydrobiopterin synthesis. An absolute requirement for cytokine induced nitric oxide generation by vascular smooth muscle. J. Biol. Chem. 36:25722-25729.

23. Blantz, R.C., and B.J. Tucker. 1978. Measurement of glomerular dynamics. In Methods in Pharmacology. Renal Pharmacology. Vol. 4. M. Martinez-Maldonado, editor. Plenum Publishing Corp., New York. pp 141-163.

24. Tucker, B.J., M.M. Mendonca, and R.C. Blantz. 1993. Contrasting effects of acute infusion on renal function in awake non-diabetic and diabetic rats. $J$. Am. Soc. Nephrol. 3:1686-1693.

25. Tucker, B.J., C.A. Mundy, A.R. Maciejewski, M.P. Printz, M.G. Ziegler,
J.C. Pelayo, and R.C. Blantz. 1986. Changes in glomerular hemodynamics response to angiotensin II after sub-acute renal denervation in rats. J. Clin. Invest. 78:680-688.

26. Moore, P.K., P. Wallace, Z. Gaffen, S.L. Hart, and R.C. Babbedge. 1993. Characterization of the novel nitric oxide synthase inhibitor 7-nitro indazole and related indazoles: antinociceptive and cardiovascular effects. $\mathrm{Br} . J$. Pharmacol. 110:219-224.

27. Thorup, C., and A.E.G. Persson. 1996. Macula Densa derived nitric oxide in regulation of glomerular capillary pressure. Kidney Int. 49:430-436.

28. Green, L.C., D.A. Wagner, J. Glogowski, P.L. Skipper, J.S. Wishnok, and S.R. Tannenbaum. 1982. Analysis of nitrate, and $\left[{ }^{15} \mathrm{~N}\right]$ nitrate and in biological fluids. Anal. Biochem. 126:131-138.

29. Bartholomew, B. 1984. A rapid method for the assay of nitrate in urine using the nitrate reductase enzyme of Escherichia Coli. Food Chem. Toxicol. 22:541-543.

30. Chomczynski, P., and N. Sacchi. 1987. Single-step method of RNA isolation by acid guanidinium thiocyanate-phenol-chloroform extraction. Anal. Biochem. 162:156-159.

31. Goto, S., T. Yamamoto, L. Feng, E. Yaoita, S. Hirose, H. Fujinaka, K. Kawasaki, R. Hattori, Y. Yui, C.B. Wilson, et al. 1995. Expression and localization of inducible nitric oxide synthase in anti-Thy-1 glomerulonephritis. Am. J. Pathol. 147:1133-1141.

32. Feng, L., Y. Xia, T. Yoshimura, and C.B. Wilson. 1995. Modulation of neutrophil influx in glomerulonephritis in the rat with anti-macrophage inflammatory protein-2 (MIP-2) antibody. J. Clin. Invest. 95:1009-1017.

33. Baylis, C., K. Engels, L. Samsell, and P. Harton. 1993. Renal effects of acute endothelial-derived relaxing factor blockade are not mediated by angiotensin II. Am. J. Physiol. 33:F74-F78.

34. Ignarro, L.J. 1989. Endothelium derived nitric oxide actions and properties. FASEB J. 3:31-36.

35. Myers, P.R., Q. Zhong, J.J. Jones, M.A. Tanner, H.R. Adams, and J.L. Parker. 1995. Release of EDRF and NO in ex vivo perfused aorta: inhibition by in vivo E. coli endotoxemia. Am. J. Physiol. 268:H955-H961.

36. Moncada, S., D.D. Rees, R. Schulz, and R.M.J. Palmer. 1991. Development and mechanism of a specific supersensitivity to nitrovasodilators after inhibition of vascular nitric oxide synthesis in vivo. Proc. Natl. Acad. Sci. USA. 88: 2166-2170.

37. Yoshizumi, M., M.A. Parrella, J.C. Burnett, and M. Lee. 1993. Tumor necrosis factor downregulates an endothelial nitric oxide synthase mRNA by shortening its half life. Cir. Res. 73:205-209.

38. Ujiie, K., L. Hogarth, R. Danziger, J.G. Drewett, P.S. Yueh, I.H. Pang, and R.A. Star. 1994. Homologous and heterologous desensitization of a guanylyl cyclase linked nitric oxide receptor in cultured rat medullary interstitial cells. J. Pharmacol. Exp. Therap. 270:761-767.

39. Westberg, G., P.J. Shultz, and L. Raij. 1994. Exogenous nitric oxide prevents endotoxin induced glomerular thrombosis in rats. Kidney Int. 46:711-716.

40. Parrillo, J.E. 1993. Pathogenetic mechanisms of septic shock. N. Engl. J. Med. 328:1471-1477.

41. Cobb, J.P., C. Natanson, W.D. Hoffman, R.F. Lodato, S. Banks, C.A Koev, M.A. Solomon, R.J. Elin, J.M. Hosseini, and R.L. Danner. 1992. $N^{\omega}$ amino-L-arginine, an inhibitor of nitric oxide synthase, raises vascular resistance but increases mortality rates in awake canines challenged with endotoxin. J. Exp. Med. 176:1175-1182.

42. Harbrecht, B.G., T.R. Billiar, J. Stadler, A.J. Demetris, J. Ochoa, R.D. Curran, and R.L. Simmons. 1992. Inhibition of nitrix oxide synthesis during endotoxemia promotes intrahepatic thrombosis and an oxygen radical-mediated hepatic injury. J. Leukocyte Biol. 52:390-394. 